\title{
Assessment of the Effect of Activated Lactoperoxidase System on Keeping Quality of Raw Cow Milk under Different Climatic Zones of Ethiopia
}

\author{
Fanta Desissa Gutema ${ }^{1,2 *}$, Hani Solomon¹, Fufa Dawo ${ }^{1}$, Takele Beyene Tufa ${ }^{3}$ and Dinka Ayana ${ }^{4}$ \\ ${ }^{1}$ Department of Microbiology, College of Veterinary Medicine and Agriculture, Addis Ababa University, Ethiopia \\ ${ }^{2}$ Department of Veterinary Public Health and Food Safety, Faculty of Veterinary Medicine, University of Ghent, Belgium \\ ${ }^{3}$ Department of Biomedical science, College of Veterinary Medicine and Agriculture, Addis Ababa University, Ethiopia \\ ${ }^{4}$ Department of Pathology and Parasitology, College of Veterinary Medicine and Agriculture, Addis Ababa University, Ethiopia
}

Submission: January 27, 2019; Published: March 20, 2019

*Corresponding author: Fanta Desissa Gutema, Department of Microbiology \& Veterinary Public Health and Food Safety, Immunology and Veterinary Public Health, College of Veterinary Medicine and Agriculture, Addis Ababa University, Bishoftu, Ethiopia

\begin{abstract}
The objective of this study was to assess the antimicrobial effect of the activated Lactoperoxidase system (LPS) on keeping quality milk under different agro-climatic zones of Ethiopia. Experimental study design was employed to assess the antimicrobial effect of LPS on the keeping quality of raw cow milk. Milk samples were collected from Addis Ababa University Business enterprise Bishoftu fattening, dairy and poultry farm. The collected milk samples were grouped into activated (treated with sodium thiocyante and Hydrogen peroxide) and non-activated (control). The activated and non-activated milk samples were subjected to four treatment groups based on the different average temperatures of the agroclimatic zones of the country namely humid zone $\left(14^{\circ} \mathrm{C}\right)$, semi-humid zone $\left(18{ }^{\circ} \mathrm{C}\right)$, semi-arid zone $\left(24^{\circ} \mathrm{C}\right)$ and arid zone $\left(37^{\circ} \mathrm{C}\right)$. The samples were incubated in adjustable incubator at each temperature. The effect of the system was evaluated using alcohol tests, total plate count and analysis of the nutritional composition of the milk every two hours. The study showed that there was a significant reduction of microbial load in LPS activated milk samples as compared to the control group ( $\mathrm{P}<0.05)$. The microbial load was decreased by 66.7\%, 75\%, 67.9\% and 64.3\% in activated milk samples kept at $37^{\circ} \mathrm{C}, 24^{\circ} \mathrm{C}, 18^{\circ} \mathrm{C}$ and $14{ }^{\circ} \mathrm{C}$, respectively. Based on the alcohol test result the LPS prolonged the shelf life of milk ranging from 6 to 12 hours without deterioration. The effect was found to be more effective in milk stored at lower temperatures. The study showed that LPS increased the shelf life of milk significantly at all temperatures $\left(18^{\circ} \mathrm{C}\right.$ and $\left.14^{\circ} \mathrm{C}\right)$. This study also revealed that application of LPS had no significant impact on the nutritional composition of milk during the storage time. In conclusion, activation of the LPS potentially decreases the microbial load and prolongs the shelf life of raw cow milk up to 6-12 hours based on the storage temperatures. Further studies should be done in different parts of the country under the specific temperatures especially in the high milk-shed areas of the country particularly in the rural settings for practical usage of the system by smallholder dairy farmers.
\end{abstract}

Keywords: Lactoperoxidase system; keeping quality; Milk; Temperature; Microbial load; Bishoftu

Abbreviations: LPS: Lactoperoxidase System; LP: Lactoperoxidase; $\mathrm{H}_{2} \mathrm{O}_{2}$ : Hydrogen Peroxide; SPC: Standard Plate Count; TBC: Total Bacterial Count;

\section{Introduction}

Lactoperoxidase (LP) is a member of the peroxidase family, a group of natural enzymes, widely distributed in nature and found in plants and animals, including humans. Its primary function is to catalyze the oxidation of certain molecules, at the expense of hydrogen peroxide, in order to generate reactive products with a wide antimicrobial activity [1]. Milk contains some essential antimicrobial factors such as lactoperoxidase, lysozyme, immunoglobulin and lactoferrin [2]. Milk is an ideal habitat for the growth and multiplication of microorganisms due to its nutritional constitution, which is rich in protein, carbohydrate, unsaturated fat, mineral and vitamins $[3,4]$. Significant losses of milk occur at the farm level during post-harvest in the form of spoilage especially in tropical and sub-tropical countries of developing countries. For instances, the cost due to milk spoilage was estimated to be $0.9-11$ million US dollars per year in Ethiopia, Uganda, Tanzania and Kenya [5].

Lactoperoxidase system (LPS) is a natural antibacterial system having both bactericidal and bacteriostatic to a wide variety of microorganisms primarily used to prevent undue bacterial multiplication thereby mitigate milk spoilage and associated 
financial loss [6-9]. The system has three primary components namely LP, hydrogen peroxide $\left(\mathrm{H}_{2} \mathrm{O}_{2}\right)$, and thiocyanate (SCN). LP catalyzes $\mathrm{H}_{2} \mathrm{O}_{2}$-dependent oxidation of thiocyanate (SCN-) to hypothiocyanite (OSCN-). The latter ion is a potent antimicrobial agent against gram-negative and gram-positive bacteria, fungi, and viruses [10]. Moreover, it has, antiviral activity, degradation of various carcinogens and protection of animal cells against peroxidative effects [1].

The most commonly used method to stop or retard the deterioration of milk on its way from the farmer to the dairy is cooling [11]. However, in many parts of the world, this is not possible for various reasons, such as lack of available capital, lack of electricity, less developed road systems, high operational costs, frequent break downs of equipment, lack of spare parts and difficulties in repair of equipment in rural areas [12]. Prevailing high ambient temperatures often further complicate the problem of milk collection in these areas [13]. This causes a considerable loss of fresh milk, and in many regions only a minor part of the production reaches the dairy industry in an acceptable condition for use as human food. In many regions most of the evening milk is spoiled after storage over-night [14].

In Ethiopia, the majority of the milk ( $98 \%$ of the national milk production and $75 \%$ of the commercial milk production) is produced by small holder dairy farmers and pastoralists. However, they are not benefiting much from the sector because of lack of cost-effective technologies such as cooling facilities [15]. Due to this fact, only $5 \%$ of the milk produced in the rural areas is marketed which is by far limiting the operation of largescale commercial dairy enterprises to their full capacity [16]. There are only few studies which were conducted in Ethiopia to evaluate the antimicrobial activity of LPS focusing to specific geographical locations. Therefore, the objective of this study was to assess the effect of LPS on keeping quality of raw cow milk under different agro-climatic zones toward the practical usage of the system in Ethiopia.

\section{Materials and Methods}

\section{Study Area}

The study was conducted from June 2017 to October 2018 in Bishoftu town. Bishoftu is located in East Shewa Zone, Oromia regional state, in the central highlands of Ethiopia. The town is located $45 \mathrm{~km}$ south east of Addis Ababa, the capital city of Ethiopia. According to 2007 census report of Ethiopia, the total population of the town was 100,114 people of which men constitute 47,938 (47.8\%) and women constitute 52,176 (52.2\%) [17]. It lies 90 $\mathrm{N}$ latitude and $400 \mathrm{E}$ longitude at an altitude of $1950 \mathrm{~m}$ above sea level. The average maximum and minimum temperature of the area is $34.7{ }^{\circ} \mathrm{C}$ and $8.5^{\circ} \mathrm{C}$ respectively, and average relative humidity is $61.3 \%$. The rainfall is bimodal. It receives an annual rainfall of $1151.6 \mathrm{~mm}$ of which $84 \%$ is received during the long rainy season covering June to September and the remaining in the short rainy season extending from March to May [18].

\section{Sample Collection}

Milk samples were collected from Addis Ababa University Business enterprise, Bishoftu fattening, dairy and poultry farm located at the college of Veterinary Medicine and Agriculture following official permission. Samples were collected during routine milking time of the farm immediately right after milking. Then after, the samples were kept in icebox containing icepacks and transported to Addis Ababa University College of Veterinary Medicine and Agriculture, Veterinary Public Health laboratory for laboratory investigations.

\section{Experimental Design}

The study employed an experimental design. Before starting the experiment, the sample was tested for bacterial load using total bacterial count (TBC) technique to know the initial microbial load. The sample was grouped into two: LPS treated (activated) and non-LPS treated (control). The LPS was activated by addition of $7 \mathrm{mg}$ of sodium thiocyanate and $10 \mathrm{mg}$ hydrogen peroxide in $500 \mathrm{ml}$ of milk samples followed by thorough mixing [7]. The milk sample from each group was subdivided into sub groups containing $0.5 \mathrm{~L}$ milk samples and kept at an average temperature representing the four agro-ecology of the country namely, an average temperature for hot, arid zone $\left(37^{\circ} \mathrm{C}\right)$, warm to hot, semi-arid zone $\left(24^{\circ} \mathrm{C}\right)$, warm to cool, semi-humid zone $\left(18^{\circ} \mathrm{C}\right)$ and cool to cold humid zone $\left(14^{\circ} \mathrm{C}\right)$ [19]. The four agro-ecological temperatures were simulated using adjustable incubators. The time of milking start of the experiment and duration of the storage during the experiment was carefully recorded. All experiments were repeated three times on different days to have estimated average value of the outcome.

\section{Evaluation of the Experiment}

Milk freshness was tested using alcohol test. For this test, $75 \%$ Ethanol was mixed with equal volume of milk [20]. The total bacterial load was estimated using the standard plate count (SPC) method. Briefly, $1 \mathrm{ml}$ from each milk sample was transferred into sterilized tubes containing $9 \mathrm{ml}$ of sterilized distilled water and properly mixed, forming 10-1 dilution. Serial dilutions were made up to $1: 10-8$ dilution level. Then, $0.1 \mathrm{ml}$ of solution was spread in to plates containing pate count agar was. The plates were placed in an incubator at $37^{\circ} \mathrm{C}$ for 48 hours. The resulting colonies were counted and expressed as colony forming units per milliliter ( $\mathrm{cfu} / \mathrm{mL}^{-1}$ ) of sample, and then the microbial counts were expressed as their logarithms. The nutritional constituents of the activated milk samples were determined using milk analyzer Lactoscan following the manufacturer's instructions.

\section{Statistical Analysis}

Statistical analysis was performed using STATA Version 20. The comparison of the effects of LPS between the experimental groups was evaluated based on one-way ANOVA analysis result by comparing the mean value of bacterial load. The effect of the system on the shelf life of milk storage without spoilage was analyzed using descriptive statistics based on the result of 
alcohol test. Percent reduction in viable count was calculated as $100 \mathrm{x}$ (viable count in the control milk at the final reduction $\mathrm{hr}$ in activated milk - viable count in the LP activated milk at the final reduction $\mathrm{hr} /$ (viable count in the control milk at final reduction $\mathrm{hr}$ in activated milk).

\section{Results and Discussion}

The study indicated that the effect of the LP system varied with temperature difference and it decreased significantly the bacterial multiplication in all temperatures as compared to the control groups $(p<0.05)$. In this study relatively higher initial bacterial load, which was beyond the recommended standard, was observed. Table 1 summarizes the mean total bacterial counts (TBC) in each group stored at different temperatures at different storage time. The reduction in bacterial load occurred within the first 3-4hrs of storage, even though the difference was not statistically significant among the different storage temperatures. The highest percentage $(75 \%)$ of reduction was observed in milk stored at $24^{\circ} \mathrm{C}$ after $8 \mathrm{hrs}$ of activation (Table 2).

Table 1: Mean total bacterial counts in activated LPS and control raw cow's milk stored at different temperatures.

\begin{tabular}{|c|c|c|c|c|c|c|c|c|}
\hline \multirow{2}{*}{ Temp } & Group & \multicolumn{7}{|c|}{ Storage Period (hr) } \\
\hline & & 0 & 2 & 4 & 6 & 8 & 10 & 12 \\
\hline \multirow{3}{*}{$37^{\circ} \mathrm{C}$} & CONT & $9.929 \pm 0.101$ & $10.073 \pm 0.101$ & $10.196 \pm 0.101$ & $10.244 \pm 0.102$ & $10.299 \pm 0.101$ & $10.336 \pm 0.101$ & $10.401 \pm 0.101$ \\
\cline { 2 - 9 } & ACT & $9.929 \pm 0.101$ & $9.996 \pm 0.101$ & $9.755 \pm 0.101$ & $9.697 \pm 0.101$ & $9.761 \pm 0.101$ & $9.859 \pm 0.101$ & $9.933 \pm 0.101$ \\
\hline \multirow{2}{*}{$24^{\circ} \mathrm{C}$} & CONT & $9.851 \pm 0.101$ & $9.970 \pm 0.101$ & $10.010 \pm 0.101$ & $10.164 \pm 0.101$ & $10.260 \pm 0.101$ & $10.314 \pm 0.101$ & $10.355 \pm 0.101$ \\
\cline { 2 - 9 } & ACT & $9.851 \pm 0.101$ & $9.899 \pm 0.101$ & $9.723 \pm 0.101$ & $9.680 \pm 0.101$ & $9.632 \pm 0.101$ & $9.689 \pm 0.101$ & $9.755 \pm 0.101$ \\
\hline \multirow{2}{*}{$18^{\circ} \mathrm{C}$} & CONT & $9.842 \pm 0.101$ & $9.955 \pm 0.101$ & $10.019 \pm 0.101$ & $10.082 \pm 0.101$ & $10.139 \pm 0.101$ & $10.197 \pm 0.101$ & $10.297 \pm 0.101$ \\
\cline { 2 - 9 } & ACT & $9.842 \pm 0.101$ & $9.951 \pm 0.101$ & $9.874 \pm 0.101$ & $9.822 \pm 0.101$ & $9.784 \pm 0.101$ & $9.780 \pm 0.101$ & $9.756 \pm 0.101$ \\
\hline & CONT & $9.925 \pm 0.101$ & $9.988 \pm 0.101$ & $10.046 \pm 0.101$ & $10.078 \pm 0.101$ & $10.150 \pm 0.101$ & $10.240 \pm 0.101$ & $10.277 \pm 0.101$ \\
\hline \multirow{2}{*}{$14^{\circ} \mathrm{C}$} & ACT & $9.925 \pm 0.101$ & $9.980 \pm 0.101$ & $9.888 \pm 0.101$ & $9.859 \pm 0.101$ & $9.823 \pm 0.101$ & $9.802 \pm 0.101$ & $9.772 \pm 0.101$ \\
\hline
\end{tabular}

CONT $=$ Control, $A C T=$ Activated

Table 2: The total bacterial load $\left(\mathrm{cfu} \mathrm{mL}^{-1}\right)$ and percentage of reduction in raw milk stored at different temperatures.

\begin{tabular}{|c|c|c|c|c|}
\hline Temperature & Group & $\begin{array}{c}\text { Initial } \\
\text { load }\end{array}$ & $\begin{array}{l}\text { Activated } \\
\text { LPS }\end{array}$ & $\begin{array}{l}\text { Percent } \\
\text { reduction }\end{array}$ \\
\hline \multirow{2}{*}{$37^{\circ} \mathrm{C}(6 \mathrm{hr})$} & Control & $9.53 \times 10^{9}$ & $1.58 \times 10^{10}$ & \multirow{2}{*}{$66.70 \%$} \\
\hline & Activated & $9.53 \times 10^{9}$ & $5.26 \times 10^{9}$ & \\
\hline \multirow{2}{*}{$24^{\circ} \mathrm{C}(8 \mathrm{hr})$} & Control & $7.55 \times 10^{9}$ & $1.84 \times 10^{10}$ & \multirow{2}{*}{$75 \%$} \\
\hline & Activated & $7.55 \times 10^{9}$ & $4.45 \times 10^{9}$ & \\
\hline \multirow{2}{*}{$18^{\circ} \mathrm{C}(12 \mathrm{hr})$} & Control & $7.16 \times 10^{9}$ & $1.987 \times 10^{10}$ & \multirow{2}{*}{$67.90 \%$} \\
\hline & Activated & $7.16 \times 10^{9}$ & $6.867 \times 10^{9}$ & \\
\hline \multirow{2}{*}{$14^{\circ} \mathrm{C}(12 \mathrm{hr})$} & \multirow{2}{*}{$\begin{array}{c}\text { Control } \\
\text { Activated }\end{array}$} & $9.71 \times 10^{9}$ & $1.96 \times 10^{10}$ & \multirow{2}{*}{$64.30 \%$} \\
\hline & & $9.71 \times 10^{9}$ & $7 \times 10^{9}$ & \\
\hline
\end{tabular}

Alcohol test also revealed similar result. It showed that the shelf life of milk was significantly improved in LPS treated groups as compared to the control counterparts $(\mathrm{p}<0.05)$. The LPS treated milk stored at temperatures of $37^{\circ} \mathrm{C}, 24^{\circ} \mathrm{C}, 18^{\circ} \mathrm{C}$ and $14^{\circ} \mathrm{C}$ had additional 4, 6, 8- and 8-hours shelf life, respectively as compared to the LPS untreated milk stored in similar condition. Analysis of the nutritional components of the activated groups of milk revealed that the application of LPS system had no significant effect on milk composition.

The study attempted to investigate and compare the keeping quality of LPS activated and inactivated control raw milk at different time intervals in the four agro-ecology of Ethiopia. The study showed that activation of raw cow milk with LPS reduces the growth of microorganisms and improved the shelf life. LPS has the ability to catalyze the oxidation of SCN by $\mathrm{H}_{2} \mathrm{O}_{2}$ with the production of antibacterial hypothiocyanate (OSCN-) [21]. The study was conducted with this context to take the advantage of the system to extend it in the country especially in different parts of the country where cooling milk is practically not feasible.

In the activated milk stored at $37^{\circ} \mathrm{C}$, the highest reduction in the total bacterial count was after $6 \mathrm{hrs}$ of storage as compared with the initial count suggesting that activation of the LPS can maintain the quality of raw milk of cows without spoilage for at least $6 \mathrm{hrs}$ by inhibiting the growth and multiplication of the general flora. This study was relatively comparable with the study of De Valdez [22] in which they found that LPS was inhibitory against microorganisms up to 8 hours in sample of bovine milk stored at $30{ }^{\circ} \mathrm{C}$. In other study, it was reported that the shelflife of LPS activated milk sample kept at $35{ }^{\circ} \mathrm{C}$ increased for 8 hours [23]. Our study revealed that the keeping quality of the milk was higher in activated milk stored at lower temperatures $\left(<18{ }^{\circ} \mathrm{C}\right)$ indicating that LPS treatment could be more effective as the storage temperature decreases. As result, the system can be used in humid and semi-humid zone mere effectively when more storage time is need particularly in selling raw milk at urban centers by rural farmers. The study agreed with other studies that reported as the shelf-life of hygienic raw milk can be increased by $4-7$ hours at $31-35^{\circ} \mathrm{C}$ by the activation of LPS and the efficacy of the LPS persists for a limited period of time, which decreases as the ambient temperature increases [24].

The alcohol stability can be used as a good indicator of milk freshness due to its reliable and consistent results [25]. It was indicated that the storage period had significant effect on alcohol test of the milk samples of the different treatments. In our study, as the storage period progressed, the milk freshness persists for 
certain period as compared to the non-treated control groups. The keeping qualities of the milk samples were not deteriorated at temperatures of $37^{\circ} \mathrm{C}, 24^{\circ} \mathrm{C}, 18{ }^{\circ} \mathrm{C}$ and $14^{\circ} \mathrm{C}$ until $6,8,12$ and 12 hours, respectively. This result showed that application of the LPS can extend the keeping quality and this agreed with other studies $[26,27]$.

Most interestingly, our study showed that the use of LPS on raw milk stored at all temperatures did not affect the nutritional composition implies that activation of milk with LPS has no impact on milk composition and thereby increases the acceptability of the system by dairy farmers and consumers. These results were in line with the findings of other study reported elsewhere [28].

\section{Conclusion}

The present study revealed that activation of raw cow milk with LPS potentially decreases the microbial load and extends the shelf life of the milk ranging from 6 to 12 hours depending on the storage temperatures. The reduction in microbial load started within the first 3-4hr of activation of LPS. The study also showed that activation of LPS has no effect on nutritional composition of milk. For practical usage of the system, it is recommended that further studies should be done in different parts of the country under the specific temperature conditions especially in the milk-shed areas particularly and the cost and benefit of LPS application. Moreover, all concerned bodies in the country should raise awareness on the importance of the system and extends the result of this study to be used by rural smallholder dairy farmers in the four agro-ecology zones of the country for improving the preservation and prevention of milk loss due to microbial spoilage so as to earn better price from milk sale by transporting to the nearby milk collection centers in different urban areas.

\section{Author Contributions}

FDG conceived the idea of the study, design the study methodology, wrote the proposal, organized the laboratory work and data collection, analyzed the data and interpreted the results, wrote the draft of the manuscript and completed the final version for submission. HS collected milk samples and participated in laboratory works. FD, TBT and DA participated in developing the research proposal and edited the final version of the manuscript before submission.

\section{Funding}

This research work was funded by Ethiopian Biotechnology institute (Ref: Ebti 30/1/10).

\section{Acknowledgment}

The authors would like to thank Addis Ababa University, College of Veterinary Medicine and Agriculture and Ethiopian Biotechnology institute for supporting this study. We also extend our thanks to w/o Tsedale Teshome for the technical support during Laboratory work.

\section{Conflict of Interest Statement}

The authors declare that there is no conflict of interest.

\section{References}

1. Kussendrager KD, Van Hooijdonk ACM (2000) Lactoperoxidase: physico-chemical properties, occurrence, mechanism of action and applications. British Journal of Nutrition 84: 19-25.

2. Quinn PJ, Markey BK, Leonard FC, Hartigan P, Fanning S, et al. (2011) Veterinary Microbiology and microbial Disease. Wiley-blackwelL, USA, pp. 400.

3. Omer RH, Eltinay AH (2008) Microbial quality of camel's raw milk in central and southern regions of United Arab Emirates. Emirates Journal of Food and Agriculture p. 76-83.

4. Boulares M, Mankai M, Hassouna M (2011) Effect of thiocyanate and hydrogen peroxide on the keeping quality of ovine, bovine and caprine raw milk. International Journal of dairy Technology 64: 52-56.

5. Lore T, Omore A, Staal S (2004) Types, levels and causes of post-harvest milk and dairy losses in sub-Saharan Africa and the Near East: Phase one synthesis report. Nairobi, ILRI, Kenya.

6. Reiter BRUNO, Marshall VM, Rosén CG (1976) Nonspecific bactericidal activity of the lactoperoxidases-thiocyanate-hydrogen peroxide system of milk against Escherichia coli and some gram-negative pathogens. Infection and Immunity 13: 800-807.

7. CAC/GL (1991) Guidelines for the preservation of raw milk by use of the lactoperoxidase system.

8. Sisecioglu M, Cankaya M, Gulcin I, Ozdemir M (2010) Interactions of melatonin and serotonin to lactoperoxidase enzyme. Journal of enzyme inhibition and medicinal chemistry 25(6): 779-783.

9. FAO, WHO (2005) Benefits and potential application of lactoperoxidase system of raw milk preservation. Report of an FAO/HWO technical meeting.

10. Köksal Z, Kalin R, Camadan Y, Usanmaz H, Almaz Z, et al. (2017) Secondary sulfonamides as effective lactoperoxidase inhibitors. Molecules, 22: 793 .

11. Lambert JC (2001) Global lactoperoxidase programme: The lactoperoxidase system of milk preservation. Bulletin of the International Dairy Federation 365: 19-20.

12. Kassa F, Yilma Z, Assefa G, Bekele T, Gojam Y, et al. (2013) Evaluation of Lactoperoxidase system as raw milk preservative at different storage temperature conditions in the central highlands of Ethiopia. Livestock Research Rural Development 25: 4.

13. Ndambi OA, Hemme T, Latacz-Lohmann U (2007) Dairying in Africa-status and recent developments. Perspectives for dairy farming systems in Africa p. 5.

14. Seifu E, Buys EM, Donkin EF (2004) Quality aspects of Gouda cheese made from goat milk preserved by the lactoperoxidase system. International Dairy Journal 14: 581-589.

15. SNV (2008) Netherlands Development Organization, Study on Investment opportunities in Ethiopia, Addis Ababa, Ethiopia.

16. Getachew F (2003) Milk and Dairy Products, Post-harvest Losses and Food Safety in Sub-Saharan Africa and the Near East. A Review of the small Dairy Sector - Ethiopia. FAO Prevention of Food Losses Programme. FAO, Rome, Italy.

17. CSA (2007) Central Statistical Authority of Ethiopia. The 2007 population and housing census result of Ethiopia. Addis Ababa: UNFPA, Ethiopia.

18. NMSA (2003) National Meteorology Service Agency. Addis Ababa, Ethiopia. 
19. Ecotravel world (2017) Ethiopia climate zones.

20. O'Connor CB (1994) Rural dairy technology. ILRI training manual No.1. International livestock Centre for Africa, Addis Ababa, Ethiopia, pp. 133

21. Ozdemir H, Hacibeyoglu HI, Uslu H (2002) Purification of lactoperoxidase from creek-water buffalo milk and investigation of kinetic and antibacterial properties. Preparative Biochemistry and Biotechnology 32: 143-155.

22. De Valdez GF (1988) Antimicrobial effect of the lactoperoxydase/thiocyanate/hydrogen peroxide (LP) system on the activity of thermophilic starter culture. Milchwissenschaft. Milk Science International 43: 350352

23. Masud T, Khalid S, Maqsood S, Bilal A (2010) Preservation of raw buffalo's milk by the activation of lactoperoxidase system and its effect on yogurt preparation. J food processing presser 34: 241-254.
24. Ponce CP (2005) Reports of field studies from Cuba and other South-American and Central-American countries presented at the technical meeting on the benefits and potential risks of the LP-system of raw milk preservation.

25. Barrett NE, Grandison AS, Lewis MJ (1999) Contribution of the lactoperoxidase system to the keeping quality of pasteurized milk. Journal of Dairy Research 66: 73-80.

26. Marks N.E, Grandison AS, Lewis MJ (2001) Challenge testing of the lac toperoxidase system in pasteurized milk. Journal of Applied Microbiology 91: 735-741.

27. Dajanta K, Chukeatirote E, Apichartsrangkoon A (2008) Effect of lactoperoxidase system on keeping quality of raw cow's milk in Thailand. International Journal of Dairy Science 3: 112-116.

28. Kumar S, Mathur BN (1989) Incidence of LP- system on the nutritional quality of milk proteins. Indian Journal of Dairy Science 42: 198-202.

This work is licensed under Creative Commons Attribution 4.0 License DOI: 10.19080/JDVS.2019.10.555796 